\title{
Integrated vector management: a critical strategy for combating vector-borne diseases in South Sudan
}

\author{
Emmanuel Chanda ${ }^{1,2^{*}}$, John M Govere ${ }^{3}$, Michael B Macdonald ${ }^{4}$, Richard L Lako ${ }^{2}$, Ubydul Haque ${ }^{5}$, Samson P Baba ${ }^{2}$ \\ and Abraham Mnzava ${ }^{4}$
}

\begin{abstract}
Background: Integrated vector management (IVM) based vector control is encouraged by the World Health Organization (WHO). However, operational experience with the IVM strategy has mostly come from countries with relatively well-established health systems and with malaria control focused programmes. Little is known about deployment of IVM for combating multiple vector-borne diseases in post-emergency settings, where delivery structures are less developed or absent. This manuscript reports on the feasibility of operational IVM for combating vector-borne diseases in South Sudan.
\end{abstract}

Case description: A methodical review of published and unpublished documents on vector-borne diseases for South Sudan was conducted via systematic literature search of online electronic databases, Google Scholar, PubMed and $\mathrm{WHO}$, using a combination of search terms. Additional, non-peer reviewed literature was examined for information related to the subject.

Discussion: South Sudan is among the heartlands of vector-borne diseases in the world, characterized by enormous infrastructure, human and financial resource constraints and a weak health system against an increasing number of refugees, returnees and internally displaced people. The presence of a multiplicity of vector-borne diseases in this post-conflict situation presents a unique opportunity to explore the potential of a rational IVM strategy for multiple disease control and optimize limited resource utilization, while maximizing the benefits and providing a model for countries in a similar situation.

Conclusion: The potential of integrating vector-borne disease control is enormous in South Sudan. However, strengthened coordination, intersectoral collaboration and institutional and technical capacity for entomological monitoring and evaluation, including enforcement of appropriate legislation are crucial.

Keywords: Malaria vector control, Integrated vector management, Policy and strategy, Community involvement, Intersectoral collaboration, Capacity building, Monitoring and evaluation, South Sudan

\section{Background}

Vector-borne diseases account for about $17 \%$ of the estimated global burden of infectious diseases [1] and exert an enormous toll on the continent of Africa [2]. They result in loss of productivity, school absenteeism, and aggravation of poverty, high costs for health care and a burden on public health services [3]. Past and current

\footnotetext{
* Correspondence: emmanuel_chanda@yahoo.co.uk

${ }^{1}$ Population Services International, Juba, South Sudan

${ }^{2}$ Ministry of Health, Juba, South Sudan

Full list of author information is available at the end of the article
}

efforts at controlling most vector-borne diseases have relied solely on disease management [4]. As neither effective medication nor vaccines are available for some of these diseases, vector control remains pivotal. Vector control is crucial to reduce the extent to which drugs are needed to treat the diseases, as the parasite can become resistant, or the drugs are often unaffordable for those most affected [5]. While vector control has a longstanding, proven record of preventing, reducing and eliminating vector-borne diseases [1], when available, vector control programmes are mostly vertical, even

\section{Biomed Central}


when and where targeted communities are afflicted by multiple diseases [6]. The need to integrate efforts and optimize the use of limited available human and financial resources is evident.

In response to the challenges, the World Health Organization's (WHO) integrated vector management (IVM) strategy, a rational decision-making process to optimize use of resources, was established as a pivotal platform for combating these often chronic and debilitating diseases [7]. The strategy is based on the premise that effective control is not the sole preserve of the health sector but of various public and private agencies, including communities. Salient attributes of IVM include: methods based on knowledge of factors influencing local vector biology; disease transmission and morbidity; use of a range of interventions, often in combination and synergistically; collaboration within the health sector and with other public and private sectors that impact on vectors; engagement of local communities and other stakeholders; a public health regulatory and legislative framework. The IVM strategy has five key elements: advocacy; social mobilization and legislation; collaboration within the health sector and with other sectors; integrated approach; evidence-based decisionmaking; and capacity building.

An IVM-based process should be cost-effective, guided by operational research and subject to routine monitoring and evaluation of impact on vector populations and disease transmission, including development of an infrastructure, financial resources and adequate human resources to manage and implement integrated vector control programmes at national and local levels [7]. As such, control programmes are encouraged to adopt and implement the approach. Since the strategy was introduced [7], and through WHO's close collaboration with member states, 68 vector-borne disease-endemic countries have established national policies for IVM [8]. To help member states re-orient to IVM and be able to meet the growing challenges amidst dwindling public-sector human and financial resources, the WHO provides technical assistance to facilitate the implementation processes [3], guidance on policy-making [6], structure for training [9] and monitoring and evaluation [10]. However, very few programmes have harnessed this approach for mounting a rational, effective and integrated operational offensive to combat multiple vector-borne diseases.

Upon the signing of the Comprehensive Peace Agreement in 2005, South Sudan has been characterized by enormous infrastructure, human and financial resource constraints and a weak health system against a huge burden of vector-borne diseases [11]. The country is thought to be one of the heartlands of vector-borne diseases in the world [12]. Communities are commonly at risk from more than one vector-borne disease. Accordingly, the Ministry of Health $(\mathrm{MoH})$ has adopted the IVM strategy to strengthen the control and prevention of these diseases [13]. While this situation invariably poses a serious challenge to socio-economic development in this postemergency setting, the presence of a multiplicity of vector-borne diseases presents a unique opportunity to explore the potential of IVM and optimize the utilization of the limited available resources, while maximizing the benefits.

A growing body of evidence demonstrates that vector control significantly reduces illness, social exclusion and mortality [14] and will thus contribute directly to the attainment of several Millennium Development Goals [15]. Therefore, this paper stresses the need for rational decision-making and sustained support for vector control in South Sudan and also serves as an archetype for other similar post-conflict environments.

\section{Case description}

A methodical review of published and unpublished documents on vector-borne diseases for South Sudan was conducted via systematic literature search of online electronic databases: Google Scholar [16], PubMed [17] and WHO [18] using a combination of search terms: 1) malaria AND IVM; 2) NTDs AND IVM; 3) NTDs AND vector control; 4) Southern Sudan OR South Sudan; 1) and 4); 2) and 4); and, 3) and 4); vector control, epidemiology, malaria, human African trypanosomiasis (sleeping sickness), visceral leishmaniasis (kala-azar), onchocerciasis (river blindness), lymphatic filariasis, dracunculiasis (Guinea worm), schistosomiasis (Bilharzia), loiasis, dengue and yellow fever. Additional non-peer reviewed literature was examined for information related to the subject.

\section{Study area}

South Sudan covers $650,000 \mathrm{sq} \mathrm{km}$ of land between $8^{\circ}$ and $18^{\circ}$ south latitude and between $20^{\circ}$ and $35^{\circ}$ east longitude with a population of 8.3 million and almost 900,000 refugees, returnees and internally displaced persons [19]. The country is landlocked in East Africa bordering the Democratic Republic of Congo in the southwest, Uganda and Kenya in the south, Central African Republic in the west, Sudan in the north and Ethiopia in the east [Figure 1]. The country's vegetation is dominated by savannah with only minor mountains. The climate is tropical with average temperatures ranging between 20 and $37^{\circ} \mathrm{C}$ and relative humidity between 26 and $88 \%$. Annual rainfall ranges between $1,000 \mathrm{~mm}$ in the south and $400 \mathrm{~mm}$ in the northern parts. Similarly, the duration of the rainy season is longest in the south (seven to eight months) and reduces towards the northern part (five to six months). Population growth rate is estimated to be $2.85 \%$ with more than $90 \%$ living on less than US\$1 per day and the 


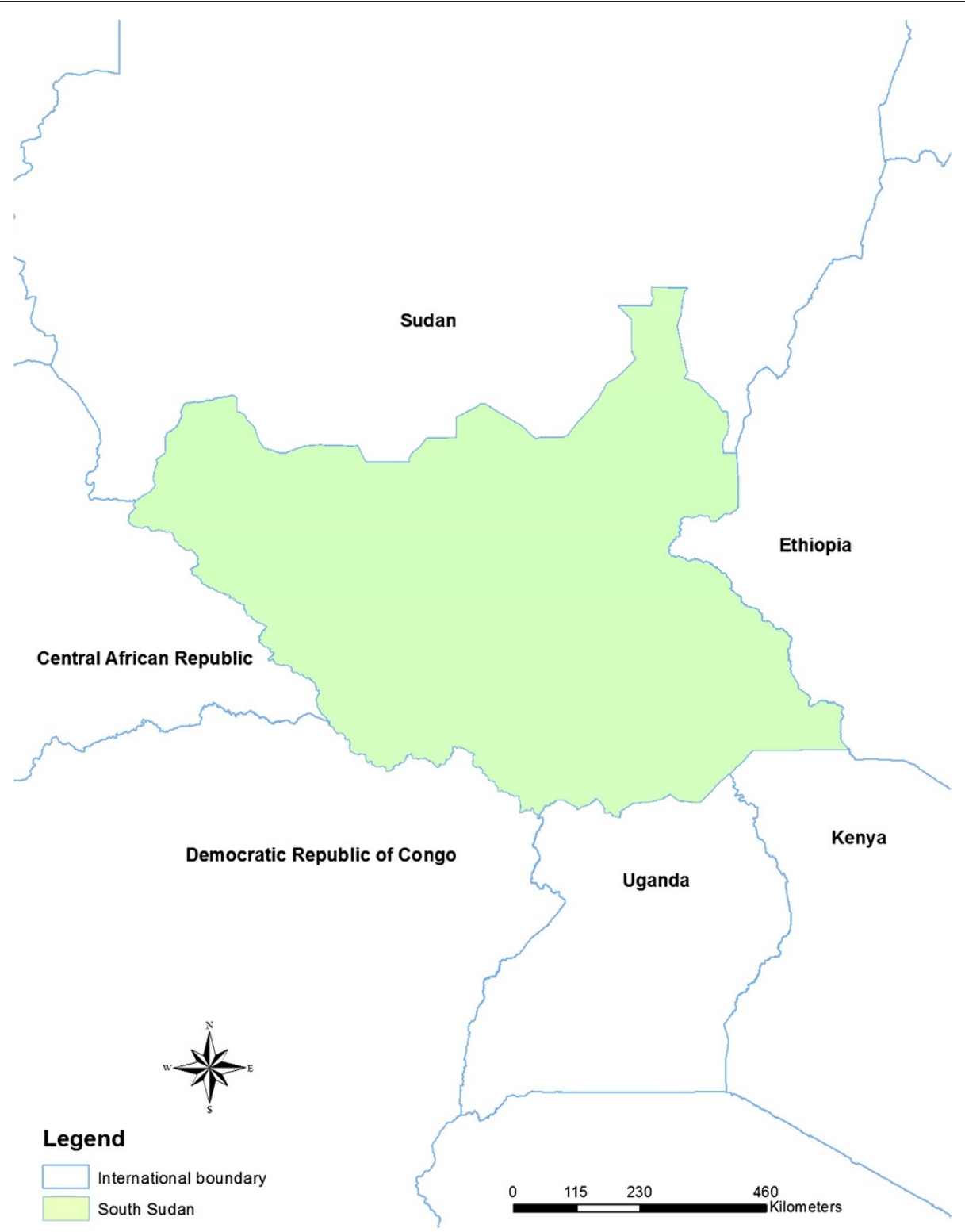

Figure 1 The map of South Sudan.

poverty rate of between 40 and 50\% [19]. Agriculture is the main source of income for more than $85 \%$ of the population. All-cause infant mortality rate is estimated at 150/1,000 live births, under-five mortality rate 250 / 1,000 live births and maternal mortality ratio 1,700 / 100,000 live births [11].

\section{The rationale for integrated vector management}

Although vector control has a proven record of reducing the burden of vector-borne diseases [7], its benefits are far from being realized because of: 1) the scarcity of skills to manage and implement vector control; 2) the development of insecticide resistance in disease vectors; and,
3) minimal or lack of collaboration between infrastructure development programmes and the health sector [20]. WHO has developed a Global Strategic Framework that sets out the principles and approaches to IVM $[7,21]$. While IVM is an acknowledged approach for the prevention and control of vector-borne diseases [22], operational experience has, to date, been from countries with relatively well-established health systems [23,24]. Little is known about deployment in post-conflict settings, where delivery structures are lacking or less developed. Very little has been done to combat multiple vector-borne diseases. South Sudan provides a unique opportunity to develop an integrated programme providing a good chance for the 
generation and establishment of entomological and epidemiological baseline data for future tracking of performance of interventions.

\section{The scale of the vector-borne disease problem}

South Sudan carries a disproportionate share of the regional and global burden of vector-borne diseases. Eleven per cent of the global burden due to vector-borne diseases is found in countries of the Eastern Mediterranean where only $8 \%$ of the global population lives. It is estimated that $4.8 \%$ of the global burden due to vector-borne diseases is contributed by South Sudan alone [22]. These statistics highlight the devastating impact of vector-borne disease on human health and socio-economic development of many communities. The world's most predominant vector-borne diseases are endemic in South Sudan with varying extents of geographical spread [12] (Table 1). Most vector-borne diseases have received global attention and the World Health Assembly (WHA) has passed resolutions (Table 2), but the problem remains enormous in South Sudan with unequal levels of control in place. Furthermore, rebuilding and rehabilitation efforts in postconflict South Sudan have predisposed people from all walks of life to vector-borne diseases.

\section{Status of IVM implementation}

Recognizing the importance of vector-borne diseases in the Eastern Mediterranean Region (EMRO), member states endorsed IVM as a regional strategic approach through a WHO Regional Committee Resolution (EM/ RC.52/R.6) in 2005 [30]. The WHO/EMRO region has demonstrated progress in translating the IVM strategy into action at national level [22]. In South Sudan, the WHO-led IVM strategy has been adopted as the main platform for the control and prevention of vector-borne diseases in accordance with the WHO framework for IVM implementation [13]. A strategic plan for IVM has been developed with the objective: "To implement IVM for the prevention of vector-borne diseases through the deployment of cost-effective and sustainable vector control interventions and strengthened intersectoral coordination, partnerships and community empowerment" [7]. However, the strategy has been minimally utilized for malaria vector control [31] due to a lack of requisite capacity for implementation and limited collaboration among stakeholders.

To improve IVM implementation, technical capacity at the national malaria control programme has been strengthened to support $\mathrm{MOH}$ undertake a comprehensive

Table 1 The burden of vector-borne diseases endemic in South Sudan

\begin{tabular}{|c|c|c|c|c|c|c|}
\hline Disease & Causative agent & Vector & Distribution & Burden & Intervention & References \\
\hline Malaria & $\begin{array}{l}\text { Plasmodium } \\
\text { falciparum P. vivax }\end{array}$ & $\begin{array}{l}\text { Anopheles gambiae, } \\
\text { An. arabiensis, } \\
\text { An. funestus }\end{array}$ & Countrywide & $\begin{array}{l}1.2 \text { million } \\
\text { cases in } 2012\end{array}$ & ITNS, IRS & {$[25]$} \\
\hline $\begin{array}{l}\text { Human African } \\
\text { trypanosomiasis } \\
\text { (sleeping sickness) }\end{array}$ & $\begin{array}{l}\text { Trypanosoma brucei } \\
\text { gambiense } \\
\text { T. b. rhodesiense }\end{array}$ & $\begin{array}{l}\text { Glossina fuscipes } \\
\text { G. tachinoides, } \\
\text { G. pallidipes, } \\
\text { G. morsitans }\end{array}$ & $\begin{array}{l}\text { Greater Equatoria Region, } \\
\text { Jonglei state (Akobo County) }\end{array}$ & $\begin{array}{l}1-2 \text { million } \\
\text { people at risk }\end{array}$ & $\begin{array}{l}\text { Introduce and } \\
\text { maintain } \\
\text { vector control } \\
\text { (tsetse traps) }\end{array}$ & {$[26,27]$} \\
\hline $\begin{array}{l}\text { Visceral } \\
\text { leishmaniasis } \\
\text { (kala-azar) }\end{array}$ & $\begin{array}{l}\text { Leishmania } \\
\text { donovani }\end{array}$ & $\begin{array}{l}\text { Phlebotomus } \\
\text { orientalis } \\
\text { P. martini }\end{array}$ & Unity, Jonglei, UN and EE & $\begin{array}{l}\text { Cyclic }(500-9,000 \\
\text { cases/year) }\end{array}$ & $\begin{array}{l}\text { LLINs in } \\
\text { highly endemic } \\
\text { communities }\end{array}$ & {$[12,28]$} \\
\hline $\begin{array}{l}\text { Lymphatic } \\
\text { filariasis } \\
\text { (elephantiasis) }\end{array}$ & $\begin{array}{l}\text { Wuchereria } \\
\text { bancrofti }\end{array}$ & $\begin{array}{l}\text { Anopheles gambiae, } \\
\text { An. arabiensis, } \\
\text { An. funestus }\end{array}$ & $\begin{array}{l}\text { Mapping not completed, } \\
\text { but probably all ten states }\end{array}$ & Unknown & $\begin{array}{l}\text { Large-scale } \\
\text { distribution of } \\
\text { LLINs for vector } \\
\text { control }\end{array}$ & {$[28]$} \\
\hline Loiasis & Loa loa & $\begin{array}{l}\text { Chrysops silacea and } \\
\text { C. dimidiata }\end{array}$ & $\begin{array}{l}\text { Equatoria region; } \\
\text { predominantly WE }\end{array}$ & Unknown & $\begin{array}{l}\text { Large-scale } \\
\text { distribution of } \\
\text { LLINs for vector } \\
\text { control }\end{array}$ & {$[12]$} \\
\hline $\begin{array}{l}\text { Onchocerciasis } \\
\text { (River blindness) }\end{array}$ & Onchocerca volvulus & $\begin{array}{l}\text { Simulium } \\
\text { damnosum }\end{array}$ & $\begin{array}{l}\text { Hyperendemic in WBEG, } \\
\text { NBEG, Warrap, Lakes, WE, } \\
\text { CE and parts of EE; } \\
\text { Parts of Unity; Jonglei } \\
\text { and UN }\end{array}$ & 4.1 million at risk & Larvicides & {$[12,28]$} \\
\hline $\begin{array}{l}\text { Dracunculiasis } \\
\text { (Guinea worm) }\end{array}$ & $\begin{array}{l}\text { Dracunculus } \\
\text { medinensis }\end{array}$ & Chrysops & $\begin{array}{l}\text { All states except WE } \\
\text { and Unity }\end{array}$ & $\begin{array}{l}3,618 \text { cases in } 2008, \\
\text { by June } 2009 \\
1,188 \text { cases reported }\end{array}$ & $\begin{array}{l}\text { Water filtration } \\
\text { and treatment of } \\
\text { water sources }\end{array}$ & {$[28,29]$} \\
\hline $\begin{array}{l}\text { Schistosomiasis } \\
\text { (Bilharzia) }\end{array}$ & $\begin{array}{l}\text { Schistosoma } \\
\text { haematobium } \\
\text { S. mansoni }\end{array}$ & $\begin{array}{l}\text { S. haematobium } \\
\text { S. mansoni }\end{array}$ & $\begin{array}{l}\text { Probably Warrab, Lakes, } \\
\text { Unity and UN }\end{array}$ & Unknown & Molluscicides & {$[12,28]$} \\
\hline
\end{tabular}


Table 2 The global burden of major vector-borne diseases and WHA resolutions for combating them

\begin{tabular}{|c|c|c|c|c|}
\hline Disease & DALYS (X 1000) & WHA resolution number & Title & Year \\
\hline Human African trypanosomiasis & 3,700 & WHA57.2 & Control of human African trypanosomiasis & 2004 \\
\hline Leishmaniasis & 2,100 & WHA60.13 & Control of leishmaniasis & 2007 \\
\hline Dracunculiasis & & WHA64.16 & Eradication of dracunculiasis & 2011 \\
\hline Lymphatic filariasis & 5,800 & WHA50.29 & Elimination of lymphatic filariasis as a public health problem & 1997 \\
\hline Onchocerciasis & 500 & WHA62.1 & Prevention of avoidable blindness and visual impairment & 2009 \\
\hline Schistosomiasis & $1,700-4,500$ & WHA54.19 & Schistosomiasis and soil-transmitted helminth infections & 2001 \\
\hline \multirow[t]{2}{*}{ Malaria } & 45,000 & WHA42.31 & Control of disease vectors and pests & 1989 \\
\hline & & WHA50.13 & $\begin{array}{l}\text { Promotion of chemical safety, with special attention to } \\
\text { persistent organic pollutants }\end{array}$ & 1997 \\
\hline Dengue & 700 & WHA55.17 & $\begin{array}{l}\text { Prevention and control of dengue and dengue haemorrhagic } \\
\text { fever }\end{array}$ & 2002 \\
\hline
\end{tabular}

situation analysis to establish vector control needs, current capacities and any gaps that need to be addressed and to put in place appropriate policies, strategies, operational guidelines and tools for IVM. An entomological laboratory and IVM monitoring system to track key vector control indicators including the development of an evidence base to inform policy recommendations is being established. Efforts to establish functional multi-disciplinary coordination mechanisms for IVM and to advocate for appropriate vector control interventions among key stakeholders have been embarked upon.

\section{Opportunities for effective IVM implementation}

Following the peace agreement after 30 years of conflict, there is a high political commitment to addressing communicable diseases, encompassing the availability of a national health policy document and a wide range of partners currently supporting various vector control activities; availability of the IVM strategic plan; good relationship with development partners and a high commitment of line ministries to jointly support vector control with the $\mathrm{MoH}$. This provides an opportunity for coordinated management of various diseases and use of different vector control tools to control specific diseases based on their sympatric occurrences. The IVM approach will strengthen the efforts by preventive chemotherapy for vector-borne neglected tropical diseases [12], improve management of insecticides and effective mitigation of potential negative health and environmental impacts, and provide a sound basis for management of insecticide resistance in disease vectors. It will enhance intersectoral accountability, leading to responsible actions among a wide range of stakeholders and provide a framework to sustain and maximize the impact of vector control interventions with optimal utilization of available resources [7].

Implementation of IVM requires explicit understanding of spatio-temporal patterns of vector-borne diseases and influencing factors that need technology that incorporates all the necessary information in an efficient manner. Geographic information system (GIS) developed from computerized cartography design systems represents an important tool for this purpose. Both GIS and associated technologies such as environmental remote sensing (RS) to characterize local conditions and also Global Positioning System (GPS) to locate ecologic features represent critical enabling technologies for epidemiologists, vector biologists and malariologists to characterize various environmental conditions and link them with vector-borne disease data in both space and time. Remotely sensed data provides important, up to date information about the environment (natural or social) in vector-borne disease control operational areas at a resolution that can rarely be obtained on the ground. Such data can be processed to provide potentially relevant information about environmental conditions critical for IVM implementation.

\section{Challenges for establishing a viable IVM strategy}

Mounting a formidable offensive against an array of chronic and debilitating vector-borne diseases is highly compromised by various reasons: environmental, sociocultural, socio-economic, technical and programmatic; a weak health system; limited access to health services; lack of accurate entomological and epidemiological data to guide vector control planning and response; pesticide management and the threat of insecticide resistance development; weak planning and coordination amongst disease control programmes; a severely constrained skilled human resource base to drive the vector control agenda forward. South Sudan's public health system and other services remain devastated from the legacy of violence and instability. The majority of the country is rural and waterlogged with a minimal or non-existent road network. Population increase, returnees, internally displaced and nomadic behaviour of people precludes effective deployment of interventions. Utilization of long-lasting insecticidal bed nets (LLINs) is compromised by their abuse/ misuse and most houses are not amenable to indoor 
residual spraying (IRS). This is further aggravated by extremely minimal intersectoral collaboration among public and private sectors including community empowerment, involvement and participation. Integration and coordination among vector-borne disease control programmes remain negligible. Appropriate requisite regulatory and legislative framework for public health is also non-existent. There is minimal evidence-based decision-making to provide technical guidance to policymakers and programme managers. Limited operational research and spatio-temporal mapping of vector-borne diseases across the country are also among the major challenges.

Effective vector-borne disease control demands for diligent entomological capacity, as such, there is need for medical entomologists and vector control specialists to spearhead IVM. South Sudan experiences a serious lack of vector control capacity at national, state and county levels. The major limitations for capacitybuilding for IVM are lack of essential physical infrastructure (insectaries, laboratories and equipment), financial resources, and technical resources (qualified vector control human resources) to support entomological monitoring and evaluation of vector control interventions. The technical assistance provided by the very few resources that exist is extremely overstretched. Addressing deficiencies in all these areas of public health capacity would be necessary for the successful implementation of IVM in South Sudan. This would need strengthened collaboration with stakeholders including local and international academic and scientific institutions and line ministries (environment and agriculture) to facilitate for entomological human resource and infrastructural strengthening.

\section{Discussion}

In response to the call by $\mathrm{WHO}$ for member states to implement the IVM strategy [7], most countries in subSaharan Africa are deploying the approach for malaria vector control $[23,24]$. Well-established IVM strategies with adherence to the five key attributes have demonstrated the enhanced impact of interventions and opened a window for leveraging additional resources [24]. Very few have harnessed the strategy for combating multiple vector-borne diseases. While the need for effective vector control in South Sudan is huge, the country provides a unique enabling environment for incorporating other diseases in the IVM approach to rationalize the use of limited available human and financial resources. Effective vector control will require operations research and implementation of new innovative tools, including improvements in geographical information systems and satellite imagery to enhance targeting of interventions. Unless all stakeholders recognize the significance of IVM and provide the resources and commitment to implement the strategy, vector-borne disease control will remain fragile in the country.

In South Sudan, limited human resource and supporting infrastructure pose great hindrance to effective IVM [11] resulting in deployment of unsuitable and poorly targeted vector control interventions with insufficient coverage and wastage of resources. Cooperation between development sectors and health sectors has been poor or non-existent. There is minimal awareness of preventive measures and surveillance for trypanosomiasis [26]. Vector control remains a major challenge for schistosomiasis as control revolves largely around the use of drugs. Insecticide usage in agriculture and poor management in public health can result in development of insecticide resistance in disease vectors and compromise vector control [32]. The WHO Pesticide Evaluation Scheme (WHOPES) advises member states on the judicious and low-risk use of pesticides and their sound management [33]. Vector control needs new environmentally friendly pesticides and resistance management strategies to address the growing challenge of insecticide resistance [32]. IVM has been recognized as the most practical approach to sustainable vector control noting the limitations normally encountered with individual characteristic interventions [33]. Within the framework of the five key attributes of IVM, there is great potential for effectively overcoming the challenges that vector control is currently facing.

Evidence-based decision-making that allows for adaptation of strategies and interventions to local vector ecology, epidemiology and resources and the prevailing socioeconomic conditions is critical [7]. Given the multiplicity of vector-borne diseases in South Sudan, including the overlapping vector bionomics and spatiotemporal distribution, effective and coordinated targeting of the most appropriate vector control interventions will require updating the geographical range of the different diseases and determining their vector species. This will facilitate the integration of vector control interventions and multidisease control approaches aimed at rational and synergistic use of available resources. This also necessitates development of an information system in which data collected is managed by $\mathrm{MoH}$ and made available to all beneficiaries [13].

While preventive chemotherapy remains the main stay of reducing the extensive morbidity associated with lymphatic filariasis (LF), onchocerciasis and schistosomiasis, vector control is critical [34]. The body of evidence pointing to the feasibility of multiple vector-borne disease control keeps increasing (Table 3). Vector control has been highly effective in the control of onchocerciasis [35], and might potentially have a significant role in elimination of LF [36]. The current scale-up of LLINs for malaria control may also reduce transmission of LF 
Table 3 Chemical-based and non-chemical vector control methods applicable in South Sudan

\begin{tabular}{|c|c|c|}
\hline Vector control method & Major vectors targeted & Vector-borne disease targeted \\
\hline Indoor residual spraying & $\begin{array}{l}\text { Indoor biting/resting female Anopheles mosquitoes; } \\
\text { phlebotomine sandflies }\end{array}$ & Malaria, lymphatic filariasis, visceral leishmaniasis \\
\hline Long-lasting insecticidal nets & $\begin{array}{l}\text { Indoor biting/resting female Anopheles mosquitoes; } \\
\text { phlebotomine sandflies }\end{array}$ & Malaria, lymphatic filariasis, visceral leishmaniasis \\
\hline $\begin{array}{l}\text { Other insecticide-impregnated } \\
\text { materials }\end{array}$ & $\begin{array}{l}\text { Anopheles, Aedes, Culex mosquitoes; phlebotomine sandflies; } \\
\text { tsetse flies; Simulium damnosum blackflies }\end{array}$ & $\begin{array}{l}\text { Malaria, dengue, lymphatic filariasis, Human African } \\
\text { trypanosomiasis, onchocerciasis }\end{array}$ \\
\hline Molluscicides & $\begin{array}{l}\text { Freshwater snails (Biomphilaria, Bulinus, Onchomelania); } \\
\text { mosquitoes Anopheles, Aedes, Culex }\end{array}$ & Schistosomiasis, lymphatic filariasis, malaria, dengue \\
\hline Insect traps & Anopheles, Aedes, Culex mosquitoes; tsetse flies & Malaria, dengue, human African trypanosomiasis \\
\hline Chemical and biological Larvicides & $\begin{array}{l}\text { Anopheles, Aedes, Culex mosquitoes; Simulium damnosum } \\
\text { blackflies }\end{array}$ & Malaria, dengue, lymphatic filariasis, onchocerciasis \\
\hline $\begin{array}{l}\text { Environmental modification/ } \\
\text { manipulation }\end{array}$ & $\begin{array}{l}\text { Anopheles, Aedes, Culex mosquitoes; freshwater snails } \\
\text { (Biomphilaria, Bulinus, Onchomelania) }\end{array}$ & Malaria, dengue, lymphatic filariasis, schistosomiasis \\
\hline House modification & Indoor biting/resting female Anopheles mosquitoes & Malaria, lymphatic filariasis \\
\hline Larvivorous fish & Anopheles, Aedes, Culex mosquitoes & Malaria, lymphatic filariasis \\
\hline Non-larvivorous natural predators & Freshwater snails (Biomphilaria, Bulinus, Onchomelania) & Schistosomiasis \\
\hline Polystyrene beads & Mosquitoes & Malaria, dengue, lymphatic filariasis \\
\hline Topical repellents & Mosquitoes; tsetse flies & Human African trypanosomiasis \\
\hline
\end{tabular}

and visceral leishmaniasis (VL). Recently, IVM has been proposed as the main strategy in areas where LF and loa loa are co-endemic and, where preventive chemotherapy is not feasible, with LLINs being the only intervention option [37]. Considering the relative toxic, expensive and lengthy treatment coupled with the slow development of new drugs and adequate diagnostic tools $[38,39]$, vector control has the potential to effectively reduce the burden of human African trypanosomiasis (HAT) and VL [40-43], but it is rarely implemented because of a lack of financial resources [27].

While provision of guidance and technical insight to policymakers and programme managers seeking to prevent, control and eliminate vector-borne diseases are key, overcoming vector-borne diseases requires interand intrasectoral collaboration, including community empowerment and participation [7]. This ensures their adequate participation in the planning, design and implementation of vector control interventions [13]. Deployment of effective and sustainable interventions would be ascertained through an appropriate regulatory and legislative framework for public health. This requires adaptation and enforcement of relevant environmental and health policies in the areas of impact assessment, agricultural policies in relation to integrated pest management and financial policies for the exemption of taxes and tariffs of vector control supplies. Effective IVM is based on the strength of intersectoral coordination. Because of the interdependency of different public and private sector organizations in relation to health and to avoid duplication of meager resources, effective coordination mechanisms and inclusion of vector control considerations in partner policies is essential.

The lack of clear career paths for entomologists in national health systems and the inadequate training of programme managers in vector control and sound management of pesticides pose operational challenges and threaten vector control efforts [9]. Capacity building for IVM has to be strengthened in order to exploit the full potential of vector control to interrupt transmission and sustain progress made in control of vector-borne diseases. It is imperative to develop essential physical infrastructure (insectaries, laboratories and capacity for operational research) and strengthen the requisite technical and programme (training in entomology and vector control) or project management skills at national and local levels. Establishment of a vector control unit in the $\mathrm{MoH}$ would suffice to set a scene for tighter integration of vector-borne disease control programmes and rigorous coordinated routine surveillance, thus providing mutual benefits and offering more effective protection against a range of different debilitating illnesses.

\section{Conclusions}

The potential for integrating vector-borne disease control is enormous in South Sudan. However, strengthened coordination, intersectoral collaboration and institutional and technical capacity for entomological monitoring and evaluation, including enforcement of appropriate legislation are crucial. Intersectoral collaboration would strengthen decision-making among policymakers, vector-borne disease control programme managers and various other 
partners. Capacity to manage public health pesticides, coordination with agriculture and adaptation of relevant policies and their enforcement, including planning and delivery of interventions is needed in South Sudan. To maximize the impact of vector control interventions, identification of relevant community perceptions and development and promotion of awareness messages for behavioural change impact is critical. There is need for a sustainable and legally recognized national IVM coordinating body with members drawn from the different sectors, together with establishing a vector control unit in the $\mathrm{MoH}$ that addresses all vector-borne diseases with clear career opportunities. This paper re-echoes the need for sustained support and also serves as an archetype for similar environments.

\section{Abbreviations \\ EMRO: Eastern Mediterranean Region; HAT: Human African trypanosomiasis; IRS: Indoor residual spraying; IVM: Integrated vector management: LF: Lymphatic filariasis; LLINs: Long-lasting insecticidal nets; MOH: Ministry of health; VL: Visceral leishmaniasis; WHA: World health assembly; WHO: World Health Organization; WHOPES: WHO pesticide evaluation scheme.}

\section{Competing interests}

The authors declare that they have no competing interests.

\section{Authors' contributions}

EC conceived the idea and drafted the manuscript; JMG, MBM, RLL, UH, SB and AM collaborated and critically reviewed the article. All authors read and approved the final manuscript.

\section{Acknowledgements}

We would like to acknowledge the staff in the various vector-borne disease control programmes for spearheading the existing vector control efforts in South Sudan. UH is supported by an A. Ralph and Sylvia E. Barr Fellowship from the W. Harry Feinstone Department of Molecular Microbiology and Immunology, Johns Hopkins Bloomberg School of Public Health.

\section{Author details}

${ }^{1}$ Population Services International, Juba, South Sudan. ${ }^{2}$ Ministry of Health, Juba, South Sudan. ${ }^{3}$ Vector Control Specialist/Consultant, Nelspruit, Mpumalanga, South Africa. ${ }^{4}$ Global Malaria Programme, World Health Organization, Geneva, Switzerland. ${ }^{5}$ W. Harry Feinstone Department of Molecular Microbiology \& Immunology, Johns Hopkins Bloomberg School of Public Health, Baltimore, MD 21205, USA.

Received: 9 July 2013 Accepted: 22 October 2013

Published: 25 October 2013

\section{References}

1. Townson H, Nathan MB, Zaim M, Guillet P, Manga L, Bos R, Kindhauser M: Exploiting the potential of vector control for disease prevention. Bull World Health Organ 2005, 83:942-947.

2. Van den Berg H, Takken W: A framework for decision-making in integrated vector management to prevent disease. Trop Med Int Health 2007, 12:1230-1238.

3. WHO: Handbook for Integrated Vector Management WHO/HTM/NTDNEM/ 2012.3. Geneva: World Health Organization; 2012. http://whqlibdoc.who.int/ publications/2012/9789241502801 eng.pdf.

4. Lawrence D: Bush's plan for tackling parasitic diseases set out. Lancet Infect Dis 2008, 8:743.

5. Matthews GA, Dobson HM, Nkot PB, Wiles TL, Birchmore M: Preliminary examination of integrated vector management in a tropical rainforest area of Cameroon. Trans R Soc Trop Med Hyg 2009, 103:1098-1104.

6. WHO: Guidance on policy-making for Integrated Vector Management. Geneva: World Health Organization; 2012.
7. WHO: Global Strategic Framework For Integrated Vector Management. WHO/ CDS/CPE/PVC/2004.10. Geneva: World Health Organization; 2004. http:// whqlibdoc.who.int/hq/2004/WHO_CDS_CPE_PVC_2004_10.pdf.

8. WHO: Public health pesticide registration and management practices by WHO Member States. (WHO/HTM/NTD/WHOPES/2011.3). Geneva: World Health Organization; 2011.

9. WHO: Core Structure for training curricula on Integrated Vector Management Geneva: World Health Organization; 2012. http://whqlibdoc.who.int/ publications/2012/9789241502788_eng.pdf.

10. WHO: Monitoring and Evaluation indicators for Integrated Vector Management. Geneva: World Health Organization; 2012. http://www.who. int/iris/bitstream/10665/76504/1/9789241504027_eng.pdf.

11. GoSS: National Health Policy Document 2007-2011. Juba: Government of Southern Sudan: Ministry of Health; 2006.

12. GoSS: Neglected Tropical Diseases and Their Control in Southern Sudan: Situation Analysis, Intervention Options, Appraisal and Gap Analysis. Juba: Government of Southern Sudan: Ministry of Health; 2008.

13. GoSS: Integrated Vector Management Strategic Plan for Southern Sudan 2007-2012. Juba: Government of Southern Sudan: Ministry of Health; 2006.

14. Van den Berg H, Takken W: Integrated vector management (IVM): from concept to practice. Malar J 2010, 9(Suppl 2):112.

15. WHO: Accelerating progress towards the health- related Millenium Development Goals. Geneva: World Health Organization; 2012. http:/www. who.int/topics/millennium_development_goals/MDG-NHPS_brochure_2010.pdf.

16. Google Scholar. http://www.google.com.

17. PubMed. www.ncbi.n/m.nih.gov/pubmed

18. WHO: Website. http://www.who.int/

19. SSCCSE: South Sudan Counts: Tables from the 5th Sudan Population and Housing Census, 2008. Southern Sudan Centre for Census: Statistics and Evaluation. Juba: Government of Southern Sudan: Ministry of Health; 2010.

20. WHO: Development of a global action plan for integrated vector management (IVM). Report of a WHO Consultation. Geneva: World Health Organization; 2009. http://whqlibdoc.who.int/hq/2009/WHO_HTM_NTD_VEM_2009.1_eng. pdf.

21. WHO: Position statement on integrated vector management. Geneva: World Health Organization; 2008. http://whqlibdoc.who.int/hq/2008/WHO_HTM_ NTD_VEM_2008.2_eng.pdf.

22. Mnzava A, Williams J, Bos R, Zaim M: Implementation of integrated vector management for disease vector control in the Eastern Mediterranean: where are we and where are we going? Eastern Mediter Health J 2011, 17:453-459.

23. Beier JC, Keating J, Githure JI, Macdonald MB, Impoinvil DE, Novak LR: Integrated vector management for malaria control. Malar J 2008, 7(Suppl 1):S4.

24. Chanda E, Masaninga F, Coleman M, Sikaala C, Katebe C, MacDonald M, Baboo KS, Govere J, Manga L: Integrated vector management: the Zambian experience. Malar J 2008, 7:164

25. RSS: Malaria programme review 2012. Republic of South Sudan: Ministry of Health; 2012.

26. Ruiz-Postigo JA, Franco JR, Lado M, Simarro PP: Human African trypanosomiasis in South Sudan: how can we prevent a new epidemic? PLoS Negl Trop Dis 2012, 6:e1541.

27. Kolaczinski JH, Kabatereine NB, Onapa AW, Ndyomugyenyi $R$, Kakembo ASL, Brooker S: Neglected tropical diseases in Uganda: the prospect and challenge of integrated control. Trends Parasitol 2007, 23:485-493.

28. Rumunu J, Brooker S, Hopkins A, Chane F, Emerson P, Kolaczinski J: Southern Sudan: an opportunity for NTD control and elimination? Trends Parasitol 2009, 25:301-307.

29. Fabiansen C, Zitta Barrella H, Vibeke C: Dracunculiasis in South Sudan. Am J Trop Med Hyg 2010, 82:757.

30. WHO: Integrated vector management: strategic framework for the Eastern Mediteranean Region 2004-2010. Cairo: World Health Organization Regional Office for the Eastern Mediteranean; 2004.

31. Chanda E, Doggale C, Pasquale H, Azairwe A, Baba S, Mnzava A: Addressing malaria vector control challenges in South Sudan: proposed recommendations. Malar J 2013, 12:59.

32. Hemingway J, Beaty BJ, Rowland M, Scott TW, Sharp BL: The innovative vector control consortium: improved control of mosquito-borne diseases. Trends Parasitol 2006, 22:308-312. 
33. WHO: WHO Pesticide Evaluation Scheme - 50 years of global leadership. Geneva: World Health Organization, 2010 (WHO/HTM/NTD/WHOPES/2010.2). http://whqlibdoc.who.int/publications/2010/9789241599276_eng.pdf.

34. WHO: Accelerating work to overcome the global impact of neglected tropical diseases: A roadmap for implementation. Geneva: World Health Organization; 2012. (WHO/HTM/NTD/2012.1). www.who.int/neglected_diseases/ NTD_RoadMap_2012_Fullversion.pdf.

35. Davies JB: Sixty years of onchocerciasis vector control: a chronological summary with comments on eradication, reinvasion, and insecticide resistance. Annu Rev Entomol 1994, 39:23-45.

36. Burkot TR: The argument for integrating vector control with multiple drug administration campaigns to ensure elimination of lymphatic filariasis. Filaria J 2006, 5:10.

37. WHO: Provisional strategy for interrupting lymphatic filariasis transmission in loiasis-endemic countries. Ghana: Report of the meeting on lymphatic filariasis, malaria and integrated vector management Accra; 2012. http://apps.who.int/iris/bitstream/10665/75139/3/WHO_HTM_NTD_PCT_ 2012.6_eng.pdf.

38. Cattand P: Tropical diseases lacking adequate control measures: dengue, leishmaniasis, and African trypanosomiasis. In Disease Control Priorities in Developing Countries. 2nd edition. Edited by Jamison T. Oxford University Press and the World Bank; 2006:451-466.

39. Torreele $E$ : To fully tackle the gang of four, needs-driven $R \& D$ is essential. PLoS Med 2006, 6:e282

40. Odiit M: Spatial and temporal risk factors for the early detection of Trypanosoma brucei rhodesiense sleeping sickness patients in Tororo and Busia districts, Uganda. Trans R Soc Trop Med Hyg 2004, 98:569-576.

41. Barrett M: The trypanosomiases. Lancet 2003, 362:1469-1480

42. Killick-Kendrick R: The biology and control of phlebotomine sand flies. Clin Dermatol 1999, 17:279-289.

43. Kishore K: Vector control in leishmaniasis. Indian J Med Res 2006, 123:467-472.

doi:10.1186/1475-2875-12-369

Cite this article as: Chanda et al.: Integrated vector management: a critical strategy for combating vector-borne diseases in South Sudan. Malaria Journal 2013 12:369.

\section{Submit your next manuscript to BioMed Central and take full advantage of:}

- Convenient online submission

- Thorough peer review

- No space constraints or color figure charges

- Immediate publication on acceptance

- Inclusion in PubMed, CAS, Scopus and Google Scholar

- Research which is freely available for redistribution 